\title{
Accelerometry and salivary cortisol response during Air Force Special Tactics Officer selection
}

\author{
John S Cuddy ${ }^{1}$, Andrew R Reinert ${ }^{2}$, Walter S Hailes ${ }^{1}$, Dustin R Slivka ${ }^{3}$ and Brent C Ruby ${ }^{1 *}$
}

\begin{abstract}
Background: Special Tactics Officer (STO) selection is conducted to select officers to enter the combat controller training pipeline. The aims were to determine physical activity patterns, estimate energy expenditure, and identify whether return and/or unsuccessful candidates demonstrated differences in cortisol responses compared to nonselected and/or first-time attendees.

Methods: Participants completed the STO selection, consisting of 5 days of physical and mental challenges. Participants were equipped with ActiCals ${ }^{\circledR}$, and saliva samples were collected throughout the STO selection.

Results: Average activity counts were $684 \pm 200$ counts. $\mathrm{min}^{-1}$, with no group differences. Estimated energy expenditure was $4,105 \pm 451 \mathrm{kcal} \cdot \mathrm{day}^{-1}$. Cortisol was elevated following extended physical training but returned to baseline during rest. Return candidates had significantly lower cortisol responses compared to first-timers, $0.43 \pm 0.06$ $\mu \mathrm{g} \cdot \mathrm{dl} \mathrm{l}^{-1}$ versus $0.76 \pm 0.18 \mu \mathrm{g} \cdot \mathrm{dl}^{-1}$, respectively, $p<0.05$.
\end{abstract}

Conclusions: An individual's salivary cortisol response to the stresses incurred during the STO selection has the potential to be incorporated into the entire picture of a candidate's performance and ability to handle stress.

Keywords: Activity monitoring, Energy expenditure, Military, Special forces

\section{Background}

United States Air Force Special Tactics Officer (STO) selection is conducted biannually in an effort to select officers who possess the necessary leadership qualities to enter the combat controller training pipeline. Combat controllers are elite Special Operations soldiers who possess a high level of fitness, specialized combat skills, sky diving, parachuting (static line and free fall), scuba training, and various weapon qualifications. Combat controllers specialize in airfield seizure and control, call for fire on targets (dropping bombs, guided weapons, artillery), controlling close air support, and target acquisition. Combat controllers work in close cooperation with other Special Operations Forces (SOF), including Army SOF and Navy Sea, Land, and Air teams. As a SOF ground combatant force, they maintain the same or higher physical attributes of strength, stamina, and endurance as other elite SOF. Identifying selection measures of SOF

\footnotetext{
* Correspondence: brent.ruby@mso.umt.edu

'Department of HHP McGill Hall, The University of Montana, Center for Work Physiology and Exercise Metabolism, 32 Campus Drive, Missoula, MT 59812, USA

Full list of author information is available at the end of the article
}

combatants is complex, but physical prowess, motivation, and spatial ability have been recognized as key factors [1]. Additionally, officers require strong leadership skills, and the ability to think clearly during stressful, ambiguous situations.

While many stressors involved in the STO selection are physical (ruck marching, pool sessions, limited caloric intake, etc.), a considerable component of the selection process is related to the qualities of mental resiliency that candidates exhibit during confusing and stressful circumstances. The difficulty of the course is compounded further by consistent sleep deprivation, magnifying the psychological/cognitive stress upon candidates. Candidates attempt to solve problems that may not have solutions and work together to achieve specific outcomes. Collectively, the physical and mental components of the STO selection combine to increase the overall stress load on candidates during the week-long selection process.

When exposed to acute physical and/or mental stresses, a cascade of hormones, including cortisol, prepares a person for physical movement and/or protection. Cortisol is a glucocorticoid that assists in partial
C Biomed Central

(C) 2013 Cuddy et al.; licensee BioMed Central Ltd. This is an Open Access article distributed under the terms of the Creative Commons Attribution License (http://creativecommons.org/licenses/by/2.0), which permits unrestricted use, distribution, and reproduction in any medium, provided the original work is properly cited. 
regulation of carbohydrate, fat, and protein metabolism, and can be used as an acute and chronic indicator of stress [2]. While diurnal fluctuation in cortisol is normal [3], an acute increase in cortisol can be caused by both psychological [4-7] and physiological [8-10] stimuli. In addition, cortisol responds to changes in training status and performance during the course of a sport season [9]. In several studies observing stress responses to simulated prisoner of war camps, Morgan et al. found acute increases in cortisol in response to stressors placed upon participants [11-14]. Cortisol increased in response to survival training stress [13], and high cortisol was associated with greater subjective distress [11], greater dissociation (transient sense that the world or the self is 'unreal') during [12] and following stress [14], and reduced military performance [12]. In elite golfers, cortisol levels increased prior to competition, but there was no relationship between cortisol levels and performance [15]. In contrast, during weightlifting competition, an acute influx of cortisol prior to competition was beneficial for improving performance [16]. It is difficult to ascertain whether increased cortisol prior to competition always improves performance [17-19], but the heightened state of being, 'fight or flight,' prepares athletes for competition. Thus, elevated cortisol levels may be beneficial or detrimental to physical and/or mental performance during stressful situations depending on the task at hand. It is likely that when tasks involve gross motor skills (i.e., weightlifters), an enhanced stress response is beneficial, whereas it may not be as helpful when fine motor skills are necessitated. During the 'fight or flight' response, cortisol directly prepares the body for movement by mobilizing glucose into the bloodstream, increasing brain's use of glucose, altering immune response, and suppressing the digestive system.

Although past research has established the typical energy expenditure [20] for military operations, descriptions of daily activity patterns have been limited [21-23]. Activity monitors can estimate energy expenditure and quantify physical activity patterns, making them a practical, simple, non-invasive research tool. The use of monitors for tracking activity has been used in diverse subject populations [21-27]. A primary advantage of using activity monitoring is the ability to classify activity into different metabolic intensities, revealing how hard participants work. Analyzing alterations of cortisol alongside activity data may provide indicators of candidates' resiliency to stressful situations.

The high physical and psychological strain associated with SOF selection provides an attractive model to quantify how the human stress response may be associated with successful task completion. Therefore, the aims of the current study were to determine physical activity patterns, estimate energy expenditure, and identify whether return and/or successful SOF candidates demonstrated differences in cortisol responses compared to non-selected and/or first-time attendees.

\section{Methods}

The research study was approved by the Institutional Review Board at The University of Montana and Air Force Research Laboratories, Wright Site Institutional Review Board. Prior to beginning the study, researchers briefed participants on the requirements for being a subject and made clear that participation in this study would in no way affect the outcome of the STO selection. Participation in the study was voluntary, and subjects provided written informed consent. Data collection took place at Hurlburt Field, FL, USA.

\section{Subjects}

Subjects were candidates $(n=11$, mass $76 \pm 6 \mathrm{~kg}$, height $177 \pm 9 \mathrm{~cm}$, and age $26 \pm 3$ years) striving to become Special Tactics Officers. Selected candidates $(N=4)$ were those picked by the cadre to enter the combat control pipeline as officers; they were chosen at the end of the selection course. Repeat $(N=3)$ and first-time attendees $(N=8)$ were designated by asking whether they had previously attended the STO selection course. Of the four successful candidates, three repeat candidates were selected, and one first-time candidate was selected. One subject was unable to pass the initial PT tests and was eliminated the first night of the study. Two subjects voluntarily eliminated themselves from the selection process on day 3 of the study. Two candidates were unable to complete the final event due to injury. One first-time nonselected candidate had to be dropped from cortisol analysis due to sample contamination at one time point. Activity data represents the six participants who completed the entire selection process (five candidates were firsttime attendees, while one was a repeat attendee), and salivary cortisol represents nine participants through day 3 and seven participants through day 5 .

\section{Experimental design}

Candidates participated in a wide range of different activities during the 5-day selection process, including: running, swimming, calisthenics, ruck marching, water skill sessions, leadership reaction courses, and 'Monster Mash' (a several-hour mission that included swimming, land navigation, ruck marching, load carrying, and skill tests). A specific time frame of events is not available for public distribution due to the need for the course to remain unpredictable and ambiguous for future candidates. During the STO selection course, subjects participated in the following: (1) pre and post body mass, (2) measurement of activity patterns by wearing $\mathrm{ActiCal}^{\circledR}$ activity 
monitors on the wrist, and (3) saliva samples were collected at 11 time points to assess changes in cortisol.

\section{Body mass and height}

Subjects' body mass was measured using a digital scale (Detecto, Model-758C, Webb City, MO, USA) at the beginning and end of the study. Height was measured using a stadiometer (Narragansett Machine Co, Providence, RI, USA). For all measurements, subjects wore socks and training shorts.

\section{Physical activity patterns and total energy expenditure}

Activity was measured by placement of a small ActiCal ${ }^{\circledR}$ activity monitor (MiniMitter, Bend, OR, USA) with an adjustable hospital band on the non-dominant wrist with the blue arrow pointing toward the elbow [28]. The wrist location has been previously used with accelerometry measurement during military research [21-23]. The monitor was worn continually for the 5-day study. Daily energy expenditure was calculated indirectly using ActiCal $^{\circledR} 2.0$ software (MiniMitter, Bend, OR), and taskspecific energy expenditure was estimated using previously established algorithms [28]. Energy expenditure for the run portion of the study was calculated using the American College of Sports Medicine running metabolic equation [29], and energy expenditure for the swim portion was calculated using the Compendium of Physical Activities [30]. Activity intensity was classified based upon the following cut points: sedentary and light (0 to $\left.144 \mathrm{kcal} \cdot \mathrm{h}^{-1}\right)$, moderate (145 to $\left.386 \mathrm{kcal} \cdot \mathrm{h}^{-1}\right)$, and vigorous $\left(387+\mathrm{kcal} \cdot \mathrm{h}^{-1}\right)$ [28]. To discriminate between energy expenditure in the sedentary and light categories, activity monitor cut points were used: sedentary $(0$ to 50 counts. $\mathrm{min}^{-1}$ ) and light (50 to 600 counts. $\mathrm{min}^{-1}$ ).

\section{Salivary cortisol}

Saliva was collected (approximately $3 \mathrm{ml}$ ) using passive drool and frozen at $-30^{\circ} \mathrm{C}$. Samples were taken following a minimum of 15 min without food or fluid intake. Prior sleep before sampling varied day to day, but participants had similar sleep opportunities and conditions. Salivary cortisol was measured using a competitive immunoassay on a micro-plate reader (Model $680 \mathrm{XR}$, Bio-Rad, Hercules, CA, USA) at $450 \mathrm{~nm}$ in accordance with the manufacturer's protocol (Salimetrics, State College, PA, USA). Salivary cortisol was collected at 11 different time points throughout the study (two times per day: upon waking (times varied) and at approximately 1,100 , see Figure 1). Though sample times varied day to day, all participants provided samples at the same time, every time. A potential limitation of the study is that sample times were not controlled each day, though the effect of the course (altered wake-rest cycles) on normal diurnal variation may dilute this limitation.

\section{Data analysis}

All descriptive data were expressed as means \pm standard deviation. A dependent $t$ test was used to determine differences in body mass from day 1 to day 5. Activity counts and energy expenditure were compared using a one-way analysis of variance across time. To compare cortisol, data across time and between repeat versus first-time candidates and selected versus non-selected were analyzed using a mixed design analysis of variance

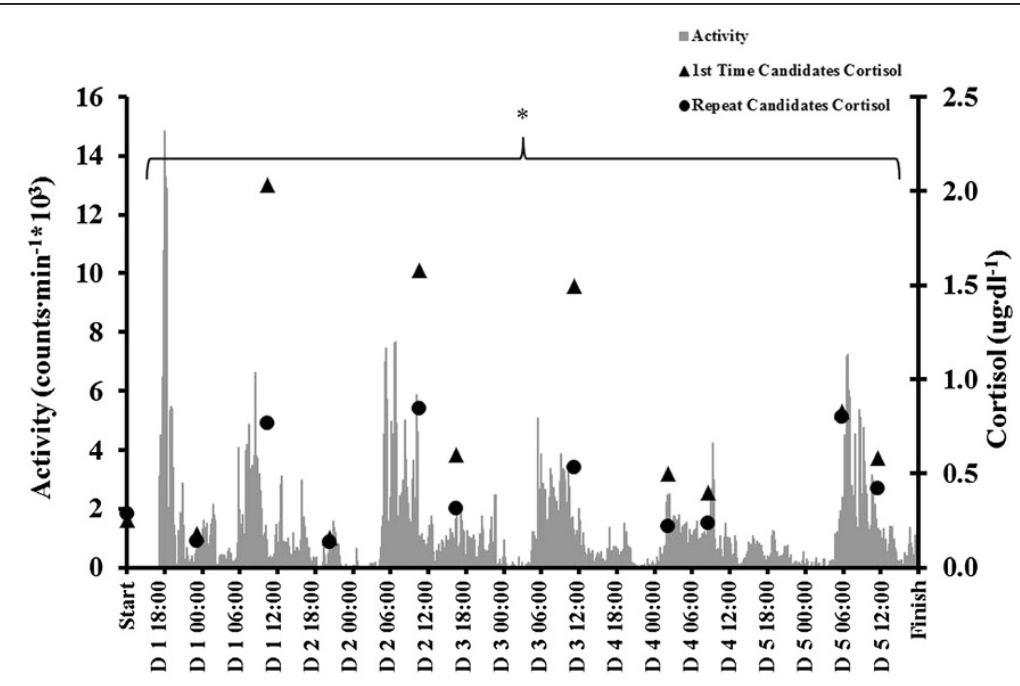

Day and Time

Figure 1 Activity and salivary cortisol during the STO selection. Single asterisk $\left(^{*}\right) p<0.05$ first-time candidate cortisol compared to repeat candidate cortisol over 5 days of the STO selection, main effect of group. 
(group $\times$ time) with repeated measures for time. The Bonferroni correction was used for the adjustment of multiple comparisons. Statistical significance was established using an alpha level of $p<0.05$.

\section{Results}

Body mass

There was no significant change in body mass $(N=7)$ from day 1 to day $5(77.8 \pm 3.1 \mathrm{~kg}$ and $77.6 \pm 3.2 \mathrm{~kg}$ for pre and post, respectively).

\section{Activity data}

The average daily activity counts for the six subjects who completed the entire selection process were $684 \pm 200$ counts. $\mathrm{min}^{-1}$. Activity during days 2 to 5 was significantly less than on day $1, p<0.05$ (Figure 2). Day 4 was lower than day $3(p<0.05)$. Time spent in different intensities and task-specific activity counts are detailed in Tables 1 and 2. Too few participants completed the 'Monster Mash' on day 5 ( $n=6$, only one candidate who was a repeat) to statistically compare between groups for activity and energy expenditure.

\section{Energy expenditure}

The average daily estimated energy expenditure for the six subjects who completed the entire selection process was $4,105 \pm 451 \mathrm{kcal} \cdot$ day $^{-1}$. Energy expenditure during days 2 to 5 was significantly less than day $1,(p<0.05$, Figure 3$)$. Day 4 was significantly lower than day $3(p<0.05)$. Energy expenditure associated with specific tasks is detailed in Table 2 .

\section{Salivary cortisol and activity}

Salivary cortisol $(N=7)$ was elevated $(p<0.05)$ compared to baseline (day 1, 13:00) following 4- to 5-h physical training sessions (time points 3,5 , and 7 ) but recovered to similar levels as baseline when candidates were provided times of reduced activity (Figure 1).

\section{Group differences}

First-time candidates $(n=6)$ had higher cortisol than return candidates $(n=3)\left(0.90 \pm 0.22 \mu \mathrm{g} \cdot \mathrm{dl}^{-1}\right.$ versus $0.43 \pm$ $0.13 \mu \mathrm{g} \cdot \mathrm{dl}^{-1}$, respectively, $\left.p<0.05\right)$ during the first 3 days (time points 1 to 7 ) (Figure 4). Two of the six first-time candidates withdrew after day 3 . When the remaining four first-time candidates were compared to the three return candidates for the entire 5-day period of the selection process, there was still a lower cortisol response for those who had previously attended, $0.43 \pm 0.06 \mu \mathrm{g} \cdot \mathrm{dl}^{-1}$, compared to $0.76 \pm 0.18 \mu \mathrm{g} \cdot \mathrm{dl}^{-1}$ for first-timers, $p<0.05$. There was a trend toward a difference between selected $(N=4)$ and non-selected candidates $(N=5)$ for cortisol, $\left(0.56 \pm 0.27 \mu \mathrm{g} \cdot \mathrm{dl}^{-1}\right.$ and $0.89 \pm 0.25 \mu \mathrm{g} \cdot \mathrm{dl}^{-1}$, respectively, $p=0.09$ ) (Figure 4).

\section{Discussion}

Special Tactics Officer selection is physically and mentally demanding, with estimated energy expenditures of $4,105 \pm 451 \mathrm{kcal} \cdot \mathrm{day}^{-1}$. Candidates appeared to do an adequate job maintaining fluid and energy balance, demonstrated by no change in body mass over the 5-day selection process. The activity data contribute to a growing body of military research using accelerometry as a way to assess activity patterns during sustained military

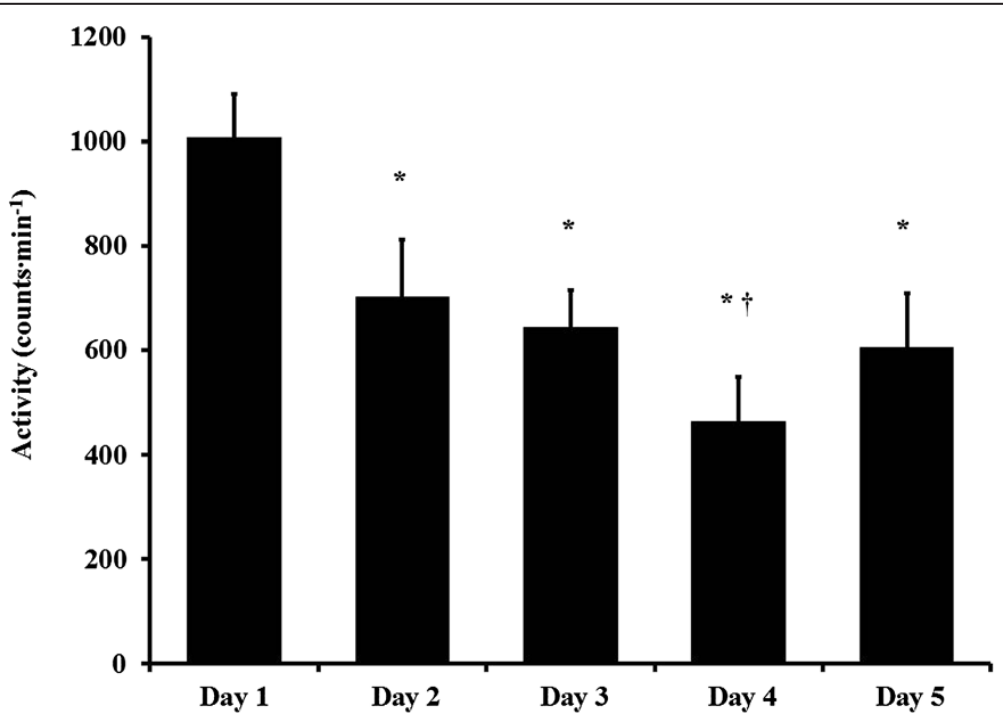

Figure 2 Activity counts during the STO selection $(\boldsymbol{n}=\mathbf{6})$. Values are expressed as mean \pm SD. Single asterisk $(*) p<0.05$ compared to day 1 . Dagger (†) $p<0.05$ compared to day 3. 
Table 1 Activity intensity profile of the STO selection

\begin{tabular}{|c|c|c|c|c|c|}
\hline Intensity & Number & Duration $\left(\mathrm{h} \cdot\right.$ day $^{-1}$ ) & Estimated energy expenditure $\left(\mathrm{kcal}^{\left.-\mathrm{day}^{-1}\right)}\right.$ & Activity (counts. $\mathrm{min}^{-1}$ ) & Percent of total time \\
\hline Sedentary & 6 & $8.7 \pm 2.0$ & $652 \pm 142$ & $16 \pm 4$ & $36 \pm 8$ \\
\hline Light & 6 & $9.3 \pm 1.4$ & $1,483 \pm 214$ & $304 \pm 14$ & $39 \pm 6$ \\
\hline Moderate & 6 & $4.7 \pm 0.5$ & $1,362 \pm 158$ & $1,493 \pm 79$ & $20 \pm 2$ \\
\hline Vigorous & 6 & $1.2 \pm 0.5$ & $608 \pm 326$ & $5,580 \pm 1,122$ & $5 \pm 2$ \\
\hline
\end{tabular}

Values are expressed as mean \pm SD.

operations [21-23]. Activity patterns are important because they can show work/rest cycles with high resolution (minute by minute), as well as intensity of activity, over an extended period of time (up to 44 days for the $\mathrm{ActiCal}^{\circledR}$ ). The primary finding in this study was that return candidates had a reduced cortisol response compared to first-time participants despite similarities in the estimated total energy expenditure (TEE) and a trend for higher activity for return candidates.

\section{Energy expenditure}

The reduction in energy expenditure over the course of the study suggests that the STO selection became progressively less physically demanding. The estimated energy expenditure in this study $\left(4,105 \pm 451 \mathrm{kcal} \cdot \mathrm{day}^{-1}\right)$ was similar to other military scenarios, with the average 4,610 \pm 650

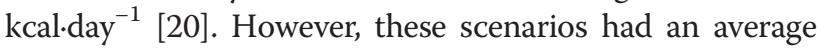
time frame of 12.2 days, whereas the current study was 5 days [20]. Previous research completed during a 10-day Marine Officer Selection Course showed a mean daily energy expenditure of $5,378 \mathrm{kcal} \cdot \mathrm{day}^{-1}\left(66.4 \mathrm{kcal} \cdot \mathrm{kg}^{-1}\right)$ [31] (calculated from doubly labeled water). In contrast, the present 5-day mean estimate for the STO selection TEE was $53 \pm 6 \mathrm{kcal} \cdot \mathrm{kg}^{-1}, 25 \%$ lower than the Marine Corps study. The $\mathrm{ActiCal}^{\circledR}$ does not account for load carriage (a substantial component of STO selection) when estimating energy expenditure, and since load carriage increases energy expenditure [32], this error may partially account for the discrepancy between studies. There were minimal, non-significant differences between groups for energy expenditure $\left(5,139 \pm 342\right.$ and $5,495 \pm 136 \mathrm{kcal} \cdot$ day $^{-1}$ for the first-time and return candidates, respectively).

\section{Activity patterns}

High levels of physical and mental stamina are necessary for completion of this course, and activity monitoring provides quantifiable data on the physical aspects of the STO selection. However, a limitation of the ActiCal ${ }^{\circledR}$ activity monitor is accurately discerning the intensity of activity when participants are carrying a load, which occurred at certain times during this study. The bulk of activity during the STO selection was light and moderate intensity, collectively making up approximately 59\% of the daily time. Vigorous activity made up approximately 71 min.day ${ }^{-1}$. The run, swim, and portions of ruck marching were the most intense physical activities during the 5-day selection process. Based on activity counts, each candidate averaged approximately $5 \mathrm{~min}$ similar to running and approximately $15 \mathrm{~min}$ similar to swimming during each ruck marching session (carrying an approximately 27-kg pack). Thus, portions of ruck marching were arduous even though the $\mathrm{ActiCal}^{\circledR}$ did not account for load carriage. Future research could determine ActiCal $^{\circledR}$ activity counts and associated energy expenditure during higher intensity activities and loaded carrying, which would provide better resolution for the metabolic intensities of the STO selection.

\section{Salivary cortisol}

During the 5 days of the STO selection, there were daily fluctuations in salivary cortisol (Figure 3), and these changes were dictated by the activity pattern prior to the collection point. The extended duration and highintensity nature of the exercise prior to time points 3,5 , and 7 explain the heightened cortisol response [8,33,34].

Table 2 Task specific activity counts, duration, and energy expenditures

\begin{tabular}{|c|c|c|c|c|c|}
\hline Activity data & Number & Sessions & Activity (counts. $\min ^{-1}$ ) & 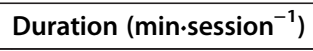 & Estimated energy expenditure (kcal.session ${ }^{-1}$ ) \\
\hline PT test calisthenics & 10 & 1 & $2,145 \pm 232$ & $31 \pm 0$ & $123 \pm 15$ \\
\hline PT test run & 10 & 1 & $13,127 \pm 2,736$ & $22 \pm 1$ & $392 \pm 30^{\mathrm{a}}$ \\
\hline PT test swim & 10 & 1 & $5,082 \pm 1,256$ & $29 \pm 3$ & $384 \pm 38^{b}$ \\
\hline Ruck marching & 9 & 3 & $1,940 \pm 350$ & $193 \pm 36$ & $769 \pm 119$ \\
\hline Pool sessions & 7 & 2 & $1,389 \pm 882$ & $183 \pm 7$ & $584 \pm 84$ \\
\hline LRC & 9 & 2 & $565 \pm 153$ & $246 \pm 37$ & $600 \pm 116$ \\
\hline Night LRC & 7 & 1 & $790 \pm 160$ & $369 \pm 0$ & $1,062 \pm 88$ \\
\hline Monster Mash & 6 & 1 & $1,789 \pm 627$ & $293 \pm 0$ & $1,155 \pm 186$ \\
\hline
\end{tabular}

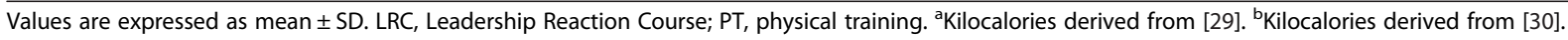




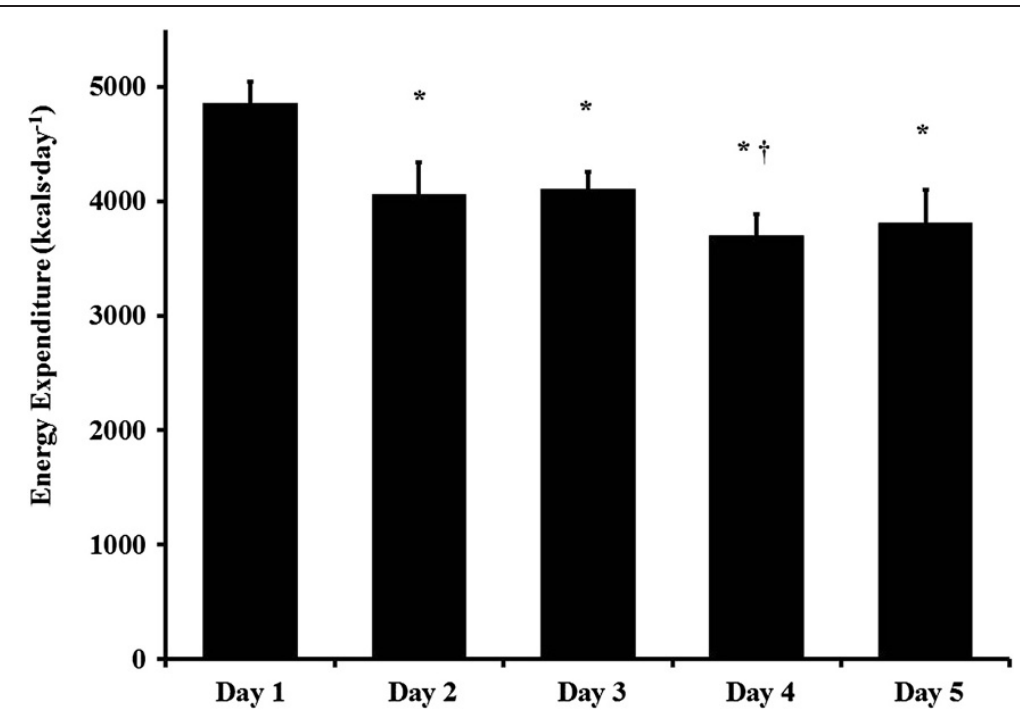

Figure 3 Estimated daily energy expenditure during the STO selection $(\boldsymbol{n}=\mathbf{6})$. Values are expressed as mean \pm SD. Single asterisk $\left(^{*}\right) p<0.05$ compared to day 1. Dagger (†) $p<0.05$ compared to day 3 .

During times of less physical demand, salivary cortisol recovered to baseline levels, indicating that candidates were well stressed from different tasks but recovered adequately. Though not statistically analyzed, of particular interest are time points 10 and 11, pre and post 'Monster Mash.' The activity data suggests ruck marching, pool sessions, and the Monster Mash are similar to one another $\left(1,940,1,389\right.$, and 1,789 counts. $\left.\mathrm{min}^{-1}\right)$. However, the salivary cortisol response to tasks on days 1,2 , and 3 (the three highest cortisol data points) is considerably higher than the post 'Monster Mash' time point. Prior to the Monster Mash, candidates had their lowest activity period $\left(298 \pm 81\right.$ counts. $\left.\mathrm{min}^{-1}\right)$ in the preceding $21 \mathrm{~h}$, including approximately $7.5 \mathrm{~h}$ of sleep. This drop in physical activity provided time for physical recovery and, combined with possible adaptation to the mental stressors, might have been the reason for a reduced salivary cortisol response [5,10]. Additionally, it is possible that in just a few days, the first-time candidates have begun to cope with the uncertainties involved with the selection course and are more comfortable with the surroundings.

It is difficult to generalize the results because of the small number of subjects per group; results could have been due to individual differences. Accepting this limitation, there was a significant difference in the cortisol response between the candidates who had previously attended the STO selection compared to the candidates

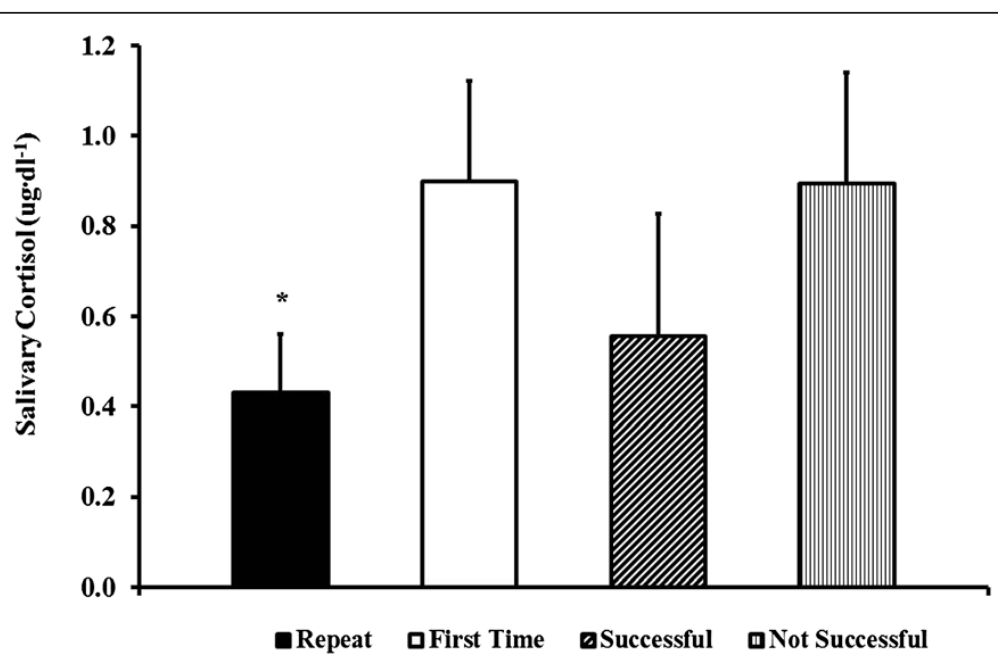

Figure 4 Mean salivary cortisol during the first 3 days of the STO selection. For return $(n=3)$, first-time $(n=6)$, successful $(n=4)$, and not successful $(n=5)$ candidates. Values are expressed as mean \pm SD. Single asterisk $\left(^{*}\right) p<0.05$ compared to First Time. 
who were attending the STO selection for the first time. Average cortisol values were $43 \%$ lower for return candidates over 5 days, suggesting a reduced response to the stressors of the STO selection despite possible higher counts.per minute for return candidates. It is difficult to ascertain a specific reason for reduced salivary cortisol levels in the returning candidates. Morgan et al. [14] suggest that SOF soldiers had a rapid release of neuropeptide- $Y$ and norepinephrine and less difference in baseline/recovery cortisol, demonstrating greater tolerance to stressors than other soldiers. These soldiers were characterized by having greater 'stress hardiness', and it is likely the return candidates in this study had been toughened by prior exposure to the STO selection. Additionally, since the candidates had a general expectation of the course (the STO selection is varied for every class), they might have had reduced anticipatory psychological stress [10] or physically prepared themselves more than first-time candidates. Thus, the physical tasks would not stress them as much, and their cortisol would return to baseline quicker than first-time candidates.

The current findings warrant further investigation. Three of the four candidates selected were return candidates; thus, it brings up the question whether reduced cortisol was a trait for return candidates or successful candidates. There was a trend for a reduced cortisol for those who were selected compared to those who were not $(p=0.09)$, and future research could expand this question with a larger study looking at the relationship of the cortisol response to the success of troops during stressful situations. Additionally, return candidates responded differently to stress and were more likely to be selected than first-time candidates $(100 \%$ of return candidates were selected, while only $12.5 \%$ of first-time candidates were selected). Prior exposure could provide an advantage for those attending for the second time, or selected candidates have certain physiological responses to stress that set them apart from non-selected candidates.

\section{Conclusions}

An estimate of the energy expenditure during the STO selection was 4,105 $\pm 451 \mathrm{kcal} \cdot \mathrm{day}^{-1}$, and cortisol increased and decreased in concert with activity patterns. Return candidates had a reduced cortisol response compared to first-time candidates, which suggests they handled stresses better. In order to apply the current data into practice, a larger study looking at the cortisol response and candidate success/failure is needed. If the results were similar to this study, commanders could use cortisol as an objective physiological marker of how well a candidate can handle stressful situations. However, given the difficulty in capturing cortisol in real-time, other real-time metrics should be explored alongside cortisol that might be easier to capture and provide objective data that could be used for decision making. In short, an individual's salivary cortisol response to the stresses incurred during the STO selection has the potential to be incorporated into the entire picture of a candidate's performance and potential to handle stress.

\section{Abbreviations}

PT: Physical training; STO: Special Tactics Officer; SOF: Special Operations Forces; TEE: Total energy expenditure..

\section{Competing interests}

The authors declare that they have no competing interests.

\section{Authors' contribution}

JC participated in study conception, data collection, statistical analysis, and drafting the manuscript. AR participated in study design and coordination/ collection of data. WH participated in data collection, statistical analysis, and drafting the manuscript. DS participated in statistical analysis and drafting the manuscript. BR participated in study conception and drafting the manuscript. All authors read and approved the final manuscript.

\section{Acknowledgments}

This project was funded by the Air Force Special Operations Command (AFSOC), Hurlburt Field, FL, USA, and by Air Force Research Laboratories FA 8650-06-1-679.

\section{Author details}

'Department of HHP McGill Hall, The University of Montana, Center for Work Physiology and Exercise Metabolism, 32 Campus Drive, Missoula, MT 59812, USA. ${ }^{2} 720$ th Special Tactics Group, 223 Cody Avenue, Hurlburt Field, FL 32544, USA. ${ }^{3}$ School of Health Physical Education and Recreation, University of Nebraska at Omaha, HPER 207R, 6001 Dodge Street, Omaha, NE 68182, USA.

Received: 19 November 2012 Accepted: 6 August 2013

\section{References}

1. Kilcullen RN, Chen G, Simsarian ST: Selection measures for special forces. Alexandria, VA: Institute USAR, Defense Technical Information Center; 1997:19-25.

2. Drucker S, New MI: Disorders of adrenal steroidogenesis. Pediatr Clin North Am 1987, 34:1055-1066.

3. Van Cauter E, Leproult R, Kupfer DJ: Effects of gender and age on the levels and circadian rhythmicity of plasma cortisol. J Clin Endocrinol Metab 1996, 81:2468-2473.

4. Haneishi K, Fry AC, Moore CA, Schilling BK, Li Y, Fry MD: Cortisol and stress responses during a game and practice in female collegiate soccer players. J Strength Cond Res 2007, 21:583-588.

5. Kunz-Ebrecht SR, Kirschbaum C, Marmot M, Steptoe A: Differences in cortisol awakening response on work days and weekends in women and men from the Whitehall II cohort. Psychoneuroendocrinology 2004, 29:516-528.

6. Lai JC, Evans PD, Ng SH, Chong AM, Siu OT, Chan CL, Ho SM, Ho RT, Chan $\mathrm{P}$, Chan CC: Optimism, positive affectivity, and salivary cortisol. $\mathrm{Br} J$ Health Psychol 2005, 10:467-484.

7. van Eck M, Berkhof H, Nicolson N, Sulon J: The effects of perceived stress, traits, mood states, and stressful daily events on salivary cortisol. Psychosom Med 1996, 58:447-458.

8. Jacks DE, Sowash J, Anning J, McGloughlin T, Andres F: Effect of exercise at three exercise intensities on salivary cortisol. J Strength Cond Res 2002, 16:286-289.

9. Maresh CM, Armstrong LE, Bergeron MF, Gabaree CL, Hoffman JR, Hannon DR, Pasqualicchio AA: Plasma cortisol and testosterone responses during a collegiate swim season. J Strength Cond Res 1994, 8:1-4.

10. Sedliak M, Finni T, Cheng S, Kraemer WJ, Hakkinen K: Effect of time-of-dayspecific strength training on serum hormone concentrations and isometric strength in men. Chronobiol Int 2007, 24:1159-1177.

11. Morgan CA 3rd, Rasmusson AM, Wang S, Hoyt G, Hauger RL, Hazlett G. Neuropeptide-Y, cortisol, and subjective distress in humans exposed to 
acute stress: replication and extension of previous report. Biol Psychiatry 2002, 52:136-142.

12. Morgan CA 3rd, Southwick S, Hazlett G, Rasmusson A, Hoyt G, Zimolo Z, Charney D: Relationships among plasma dehydroepiandrosterone sulfate and cortisol levels, symptoms of dissociation, and objective performance in humans exposed to acute stress. Arch Gen Psychiatry 2004, 61:819-825.

13. Morgan CA 3rd, Wang S, Mason J, Southwick SM, Fox P, Hazlett G, Charney DS, Greenfield G: Hormone profiles in humans experiencing military survival training. Biol Psychiatry 2000, 47:891-901.

14. Morgan CA 3rd, Wang S, Rasmusson A, Hazlett G, Anderson G, Charney DS: Relationship among plasma cortisol, catecholamines, neuropeptide $Y$, and human performance during exposure to uncontrollable stress. Psychosom Med 2001, 63:412-422.

15. McKay JM, Selig SE, Carlson JS, Morris T: Psychophysiological stress in elite golfers during practice and competition. Aust J Sci Med Sport 1997, 29:55-61.

16. Passelergue P, Robert A, Lac G: Salivary cortisol and testosterone variations during an official and a simulated weight-lifting competition. Int J Sports Med 1995, 16:298-303.

17. Edwards DA, Wetzel K, Wyner DR: Intercollegiate soccer: saliva cortisol and testosterone are elevated during competition, and testosterone is related to status and social connectedness with team mates. Physiol Behav 2006, 87:135-143.

18. Elloumi M, Maso F, Michaux O, Robert A, Lac G: Behaviour of saliva cortisol $[C]$, testosterone $[T]$ and the $T / C$ ratio during a rugby match and during the post-competition recovery days. Eur J Appl Physiol 2003, 90:23-28.

19. Filaire E, Alix D, Rouveix M, Le Scanff C: Motivation, stress, anxiety, and cortisol responses in elite paragliders. Percept Mot Skills 2007, 104:1271-1281.

20. Tharion WJ, Lieberman HR, Montain SJ, Young AJ, Baker-Fulco CJ, Delany JP, Hoyt RW: Energy requirements of military personnel. Appetite 2005, 44:47-65.

21. Hoyt RW, Opstad PK, Haugen AH, DeLany JP, Cymerman A, Friedl KE: Negative energy balance in male and female rangers: effects of $7 \mathrm{~d}$ of sustained exercise and food deprivation. Am J Clin Nutr 2006, 83:1068-1075.

22. Lieberman HR, Kramer FM, Montain SJ, Niro P: Field assessment and enhancement of cognitive performance: development of an ambulatory vigilance monitor. Aviat Space Environ Med 2007, 78:B268-B275.

23. Lieberman HR, Falco CM, Slade SS: Carbohydrate administration during a day of sustained aerobic activity improves vigilance, as assessed by a novel ambulatory monitoring device, and mood. Am J Clin Nutr 2002, 76:120-127.

24. Cuddy JS, Gaskill SE, Sharkey BJ, Harger SG, Ruby BC: Supplemental feedings increase self-selected work output during wildfire suppression. Med Sci Sports Exerc 2007, 39:1004.

25. Gunn SM, van der Ploeg GE, Withers RT, Gore CJ, Owen N, Bauman AE, Cormack J: Measurement and prediction of energy expenditure in males during household and garden tasks. Eur J Appl Physiol 2004, 91:61.

26. Puyau MR, Adolph AL, Vohra FA, Zakeri I, Butte NF: Prediction of activity energy expenditure using accelerometers in children. Med Sci Sports Exerc 2004, 36:1625

27. Schmitz KH, Treuth M, Hannan P, McMurray R, Ring KB, Catellier D, Pate R: Predicting energy expenditure from accelerometry counts in adolescent girls. Med Sci Sports Exerc 2005, 37:155.

28. Heil DP: Predicting activity energy expenditure using the Actical activity monitor. Res Q Exerc Sport 2006, 77:64.

29. Mahler DA, Froelicher VF, Houston Miller N, York TD, Kenney LW, Humphrey $\mathrm{RH}$, Bryant CX: ACSM's guidelines for exercise testing and prescription. Baltimore: Williams and Wilkins; 1995.

30. Ainsworth BE, Haskell WL, Whitt MC, Irwin ML, Swartz AM, Strath SJ, O'Brien WL, Bassett DR Jr, Schmitz KH, Emplaincourt PO, Jacobs DR Jr, Leon AS: Compendium of physical activities: an update of activity codes and MET intensities. Med Sci Sports Exerc 2000, 32:S498.

31. Hoyt RW, Buller MJ, Delany JP, Stultz D, Warren K, Hamlet MP, Shantz D, Tharion WJ, Smith P, Smith B: Warfighter physiological status monitoring (WPSM): Energy balance and thermal status during a 10-day cold weather U.S. Marine Corps infantry officer course field exercise. Natick, MA: U.S. Army Research Institute of Environmental Medicine; 2000:1-59.

32. Patton JF, Kaszuba J, Mello RP, Reynolds KL: Physiological responses to prolonged treadmill walking with external loads. Eur J Appl Physiol Occup Physiol 1991, 63:89-93.
33. Tremblay MS, Copeland JL, Van Helder W: Influence of exercise duration on post-exercise steroid hormone responses in trained males. Eur J Appl Physiol 2005, 94:505-513.

34. Venkatraman JT, Feng X, Pendergast D: Effects of dietary fat and endurance exercise on plasma cortisol, prostaglandin E2, interferon-gamma and lipid peroxides in runners. J Am Coll Nutr 2001, 20:529-536.

10.1186/2046-7648-2-28

Cite this article as: Cuddy et al:: Accelerometry and salivary cortisol response during Air Force Special Tactics Officer selection. Extreme Physiology \& Medicine 2013, 2:28

\section{Submit your next manuscript to BioMed Central and take full advantage of:}

- Convenient online submission

- Thorough peer review

- No space constraints or color figure charges

- Immediate publication on acceptance

- Inclusion in PubMed, CAS, Scopus and Google Scholar

- Research which is freely available for redistribution 